\author{
Military Technical College \\ Kobry Elkobbah, Cairo, \\ Egypt.
}

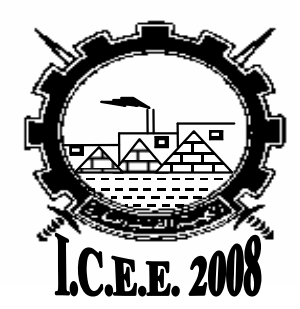

$4^{\text {th }}$ International Conference On Chemical \& Environmental Engineering 27-29 May 2008

\title{
OPTICAL ABSORPTION OF GAMMA IRRADIATED SOLID SUGAR
}

\author{
M. A. El-Ahdal ${ }^{\star}$, A. A. Baraka ${ }^{\star \star}$ and I. M. Khalil ${ }^{* \star \star}$
}

\begin{abstract}
In the case of radiation emergency, a sugar method, with readout by UV spectra analysis as personnel monitor for the affected population, is proposed. Characteristics of the method are economics, universal availability and portability, with quantitative monitoring characteristics for ionizing radiation. Relative simplicity of the procedure for evaluating dose to individuals or to households after irradiation and readout was used this widely available and compact monitor. In this study, the simpler optical absorption studies show the presence of a distinctive band in the UV region $(269 \mathrm{~nm})$, whose intensity changes with the irradiation dose. The dose linearity of the sugar solution with the absorbance at peak is experimentally verified from $0.25 \mathrm{~Gy}$ to $40 \mathrm{kGy}$. Fading effect was studied for all the used radiation range. These results might be interpreted in terms of the formation of free radicals and possible chain scission and crosslinking along the sugar molecular chains. The optical energy gap and Urbach energy of the sugar solution also investigated. Dose (D) absorbance difference $\left(A-A_{\circ}\right)$ relationship may be followed up using the two equations $A-A_{0}=0.0439 D(k G y)+0.054$, with linear regression 0.969 in the dose range from $0.25 \mathrm{kGy}$ to $2.0 \mathrm{kGy}$ and $\mathrm{A}-\mathrm{A}_{0}=0.0165 \mathrm{D}(\mathrm{kGy})+0.173$ with linear regression 0.9660 in the dose range from $2.0 \mathrm{kGy}$ to $40 \mathrm{kGy}$.
\end{abstract}

\section{KEY WORDS}

Dosimetry ; Gamma radiation; Suger; UV-analysis.

\footnotetext{
* Radiation Protection and Dosimetry Department, National Centre for Radiation Research and Technology

** Egyptian Armed forces.

${ }^{* * *}$ Egyptian Atomic Energy Authority
} 


\section{INTRODUCTION}

Occupational workers in nuclear fields (radiological accident) wear a personal dosimeter and work areas are constantly monitored. However, the general public are not monitored in their daily lives, thus it is difficult to estimate external dose in the case of a nuclear accident or a radiation emergency situation. Sucrose and common household sugars (e.g. cane) have been studied as dosimeters for a wide variety of applications. Previous studies on sugar as a potential materials for dosimetry properties are reported [1-2].

Electron spin resonance (ESR) technique is a suitable technique for dose estimation in such cases. Many kinds of organic and inorganic materials have been selected for the measurement of radicals formed on irradiation. Sucrose was found to be one of the suitable materials that satisfy conditions as a dosimeter [3-9].

Sucrose, $\mathrm{C}_{12} \mathrm{H}_{22} \mathrm{O}_{11}$, consists of the dimmer glucose - fructose [10], linked by one oxygen atom, which constitute the glucosidic binding between the hydroxyl group $(-\mathrm{OH})$ of the sugar and the carbon of carbonyl radical $(\mathrm{O}=\mathrm{C}-\mathrm{H})$ :

$$
\underset{\text { saxrosese }}{1 \mathrm{C}_{12} \mathrm{H}_{22} \mathrm{O}_{11}}+\mathrm{H}_{2} \mathrm{O} \rightarrow \underset{\text { glixose }}{1 \mathrm{C}_{6} \mathrm{H}_{12} \mathrm{O}_{6}}+\underset{\text { fructose }}{1 \mathrm{C}_{6} \mathrm{H}_{12} \mathrm{O}_{6}} \text {. }
$$
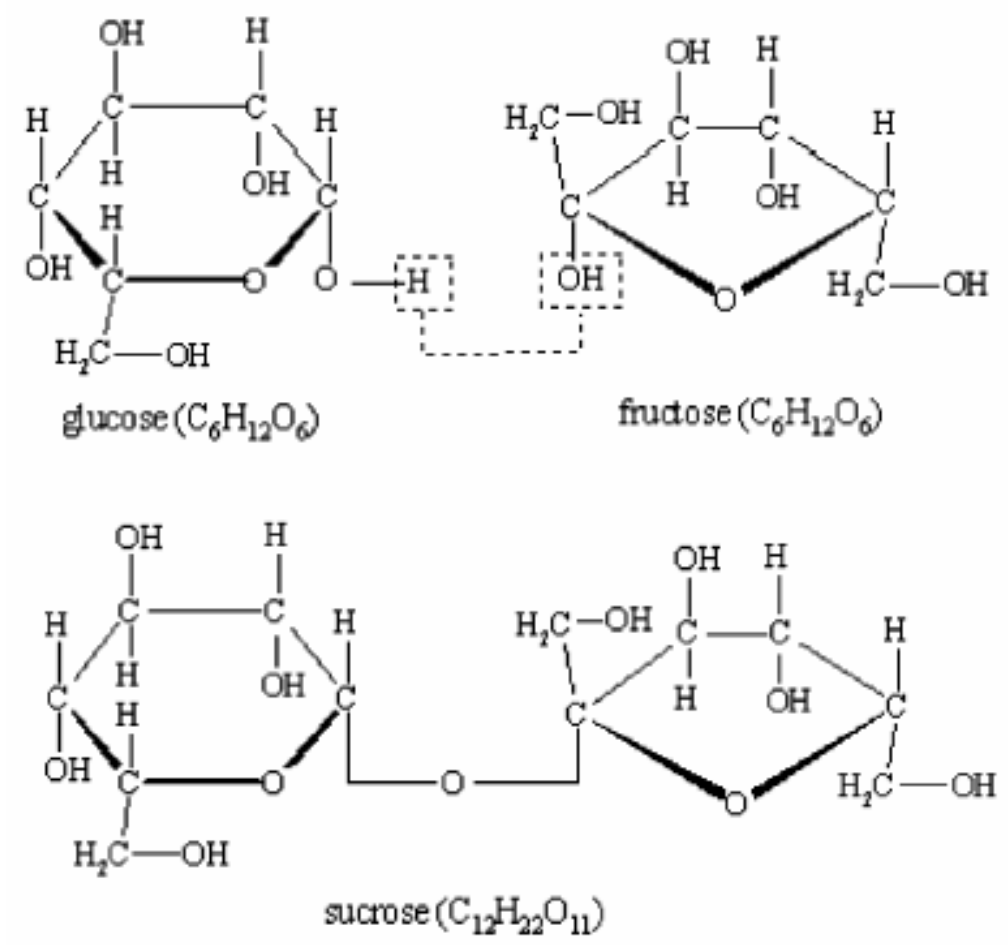

The goal of this study is to achieve the possible measurement of the Egyptian sugar for the dosimetric purposes. 


\section{Material and methods}

In this work highest grade sugar cane not yet completely characterized for dosimetry purposes, purchased from a local market. Optical absorption measurements were obtained at room temperature with a Shimadzu model UV $160 \mathrm{~A}$ double-beam recording spectrophotometer. It has a spectrum ranged from $190 \mathrm{~nm}$ to $1100 \mathrm{~nm}$. A cell of $1 \mathrm{~cm}$ thickness is used. Average reading of three samples for each measurement to define the standard deviation was performed.

This work uses the dose response curve method for dose reconstruction since it is a non-destructive fast method and the variation of radiation sensitivity of sugar is independent of the applied dose evaluation method. The parameters of the calibration curve, slope and interception with dose axis were determined by linear regression analysis.

Irradiation were carried out with gamma radiation in the gamma chamber 5000 Board of radiation and isotope technology, (BrIT), D.A.E, Mumbai India. Activity: 12000 curies 1998. The absorbed dose rate in the irradiation facility is $3 \mathrm{kGy} / \mathrm{h}$.

After irradiation, the solid sugars were put in special containers to avoid exposure to light. For fading study, two aqueous solutions are prepared. First solution is called fresh solution prepared only before measuring the UV spectrum. Second one prepared after irradiation, stored and measurement was performed with time and called once solution.

\section{Results and Discussion}

The absorbance spectrum of sugar aqueous solution, of concentration $5 \%$, in the wavelength from $190 \mathrm{~nm}$ to $1100 \mathrm{~nm}$ was plotted as shown in Fig.1. A peak at $269 \mathrm{~nm}$ was obtained. absorbance spectra of sugar solutions of different concentrations (5-5\%) were prepared. Figure 2 showed a linear relation between the absorbance at peak and the concentration. Such relation has a linear regression 0.99 and can be followed by using the equation:

$A=0.01368 C-0.0068$

Where $A$ is the absorbance at peak and $C$ is the percentage concentration.

Sample $5 \%$ solution of fresh prepared sugar was chosen to study the effect of gamma radiation. Feature of the absorbance spectrum of sugar aqueous solution is dependent on gamma radiation dose where a set of peaked spectra at $269 \mathrm{~nm}$ was obtained. Absorption bands of this spectral region are typically associated to carbonyl groups in organic compounds [10].

To clear the effect of gamma radiation on the sugar absorbance spectra, the absorbance difference at peak is used as $\left(A-A_{\circ}\right)$ where $A$, represents the peak absorbance of irradiated sugar while $A_{o}$ is the un-irradiated reading. 
The influence of post-irradiation storage on the radiation UV response of the sugar was investigated. The samples were measured immediately after irradiation at room temperature and subsequently measured each day for ten days.

Measurements of fresh solution prepared from irradiated solid sugar after different times from irradiation are shown in Fig.3. A set of linear relations between $\left(A-A_{0}\right)$ and gamma dose for different times from irradiation are obtained over ten days. In case of once samples (Fig.4), the linearity between absorbance and gamma dose disturbs after 4 days.

Fading effect of fresh solution was illustrated as in figure 5. A gradual increase of (A$A_{o}$ ) with time after irradiation continues up to 7 days after which it showed a gradual decrease. This feature repeated for different gamma doses (except for $8 \mathrm{kGy}$ and 10 $k G y$, a plateau starts to appear after 6 days up to 8 days) with an increase of $\left(A-A_{\circ}\right)$.

For once solution (Fig. 6), a certain stability of the absorbance difference takes place after 6 days from irradiation up to 8 days. Such results agree with the findings obtained by Yordanov and Karakirova [8].

The present study shows that the response coefficient of $5 \%$ sugar solution in $1 \mathrm{~cm}$ sample cell is $0.017 / \mathrm{kGy}$ for solution directly read after irradiation (Fig.7). Over ten days such response decreases into $0.015 / \mathrm{kGy}$ for fresh sample over 10 days and increased to $0.023 / \mathrm{kGy}$ for once samples over 4 days.

From the dosimetry point of view the knowledge of time stability of radiation induced UV spectrum may be explained on the basis of production of free radicals by irradiation as well as their decay kinetics with time after irradiation [8]. The investigation of dosimeter stability is important because the evaluation of the absorbed dose of high energy irradiation not only immediately after irradiation but also to be archived for future inspection. There are two mechanisms of decay of the monitored free radicals:

- recombination with other paramagnetic species to give diamagnetic products;

- transformation into another paramagnetic molecules.

Transformation of the induced free radicals, during irradiation, occurs in the crystalline volume forming another paramagnetic species. Dissolving the solid sugar in water ( $5 \%$ fresh sample) initiates a growth of the free radical by the water radiolysis. Recombination of the species gradually starts, after 6 days from gamma irradiation, producing diamagnetic species. Such mechanism continues up to $8 \mathrm{kGy}$ and $10 \mathrm{kGy}$. For these doses, we found that in the time range from 6 days to 8 days rate of recombination increases (nearly stable absorbance reading) followed with the decrease of the free radicals. Such later behavior may be due to the absorption of ultraviolet light or thermal energy as seen later. Also, the increase and decrease of the absorbance may be interpreted as a crosslinking and chain scission along the sugar molecular chains is presented.

In case of once sample, rate of increasing the absorbance was accelerated and a stable region in the time range from 6 day and 8 after irradiation for all irradiation doses was appeared. 
The optical absorption coefficient (a) calculated from the optical transmission spectrum can be used to determine the corresponding energy gap ( $\mathrm{Eg})$ from the optical transition theory [10],

$(\alpha h v)^{2}=B(h v-E g)$

Where $h_{2}$ is the incident photon energy in eV and $B$ is a parameter depends on the transition probability. The full spectra of once solution of irradiated sugar are plotted in Fig.8. The band at $269 \mathrm{~nm}$ is well defined while two broad bands in the infrared region are also appeared. The infrared bands are disturbed by irradiating the sugar, i.e. sample sensitive to thermal influences. A plot of $(\alpha h v)^{2}$ versus the photon energy (hv), was shown in fig.10, indicating that the samples under investigation were characterized by a direct allowed transition. The corresponding energy gap $\left(E_{g}\right)$ was obtained from the intersection of the linear part photon energy axis. The variation of the optical energy gap with gamma doses was illustrated in fig.11. The results indicated an independent behavior of the sugar energy gap on the gamma doses and $E_{g}=5.37 \pm 0.068$.

In many crystalline and non-crystalline semiconductors [10], the absorption coefficient, $\alpha$, depends exponentially on the photon energy (hv). The exponential dependence known as the Urbach rule may be written in the form [11]:

$\alpha=B \exp \left(h v / E_{e}\right)$

Where $E_{e}$ is the width of the band tails (Urbach energy) of the localized states. Relation between In $(\alpha)$ and $h v$, was drawn and the value of $E_{e}$, for different irradiation doses, can be calculated from the reciprocal of the slope of the linear region of such plots (Fig.12). The variation of the Urach energy with gamma doses was shown in fig.13. The Urbach energy was used to characterize the width (density) of the localized state in the band gap and gives an impression about the degree of disorder (which would depend on the thermal history of the sample) in amorphous and crystalline systems. Materials with larger Urbach energy have greater tendency to convert weak bonds into defects. Urbach energy deduced from the band at $269 \mathrm{~nm}$ confirming the disturbance of the irradiated sugar. Also gives an impression about influence of the exposure of sugar to the environment light.

Other works based on infrared studies [10] have reported that for irradiated sucrose the absorbance maxima whose intensity increases with the irradiation dose as has also been observed in the present work are associated with the presence of molecular radiolysis products containing carbonyl groups. Result points out to the formation of these carbonyl groups in the glucose moiety of the sucrose, among other possible radiolysis products that have been observed in glucose and fructose. As mentioned before a possible assignment could be a scission at the $C_{1}$ carbon of the glucose moiety.

Lower doses than $2 \mathrm{kGy}$ are investigated by choosing sugar solution with concentration $20 \%$ to obtain an appreciable absorbance. Spectra are characterized with a broad peak at $269 \mathrm{~nm}$ and their absorbance difference are reported against different doses $(0.25-1.75 \mathrm{kGy})$ for different times after irradiations as shown in 
Fig.13. The negative absorbance difference means the bleaching of sugar solution as a result of effect of the environmental conditions. Such bleaching may be due to the presence of low concentration of absorbent species, at the defect state of energy, upon gamma irradiation. The observed data showed linear relations which are accompanied with an approximately stable absorbance after 1 day from irradiation (Fig.14).

Response coefficient of $20 \%$ sugar solution in $1 \mathrm{~cm}$ sample cell sugar solution is $0.0221 / \mathrm{kGy}$ (Fig.15). Such coefficient reached to $0.154 / \mathrm{kGy}$ over 8 days then it became $0.103 / \mathrm{kGy}$ after 2 days.

\section{CONCLUSION}

A study has been carried out about the effects of gamma irradiation on commercial sugar. Linear relation between the absorbance and gamma radiation dose $(0.25$ $10 \mathrm{kGy}$ ) was obtained. Linear relations are dominated over 10 days after irradiation for fresh samples. On the other hand, this linearity is disturbed after 4 days for once solution. Fading data showed the stability of absorbance readings during three days (6-8 days after irradiation) specially for once samples.. Response coefficients decreased into $0.015 / \mathrm{kGy}$ for fresh sample over 10 days and increased to $0.023 / \mathrm{kGy}$ for once samples over 4 days. Dose- absorbance relationship (Fig.16) may be followed up using the equation:

$A-A_{0}=0.0439 D(k G y)+0.054$

with linear regression 0.969 in the dose range from $0.25 \mathrm{kGy}$ to $2.0 \mathrm{kGy}$.

$A-A_{0}=0.0165 D(k G y)+0.173$

with linear regression 0.9660 in the dose range from $2.0 \mathrm{kGy}$ to $40 \mathrm{kGy}$.

Our findings are supported on the basis of some previous works made using infrared and ESR techniques. The optical energy gap and the Urbach energies are taken part in the explanation of the results.

\section{REFERENCES}

[1] N.D. Yordanov and E. Georgieva, EPR and UV spectral study of gamma irradiated white and burned sugar, fructose and glucose, Spectrochem. Acta, A 60(2004) 1307-1314.

[2] N.D. Yordanov, V. Gancheva and E. Georgieva, EPR and UV spectroscopic study of table sugar as a high dose dosimeter, Radiat. Phys. Chem. 65, (2002a) 269-276.

[3] Nakajima, T. (1988), Health Phys., 55 , 951-955.

[4] Shiraishi, K. (1998), Advances in ESR Applications 14, 4-12.

[5] Flores C. J., Cabrera E.B., Calderón T., Muñoz E. P., Adem E., Hernández J.A., Boldú J. L., Ovalle P.M. and Murrieta H.S. (2000), ESR and optical absorption studies of gamma- and electron-irradiated sugar crystals, Volume 52, Issue 5 , 15, Pages 1229-1234. 
[6] N.D.Yardavov and Y.KaraKirova, Sugar/UV spectrophotometric system for high energy dosimetry (0.055-160kGy), Radiation measurements 42 (2007) 121-122.

[7] M.A. El-Ahdal, Effect of Gamma Radiation Dose on Sugar, Arab Journal of Nuclear Science and Applications, 36, 2 (2006)230.

[8] N. D. Yordanov and Elka Georgieva EPR and UV spectral study of gammairradiated white and burned sugar, fructose and glucose, Spectrochimica Acta Part A: Molecular and Biomolecular Spectroscopy, Volume 60, Issue 6, May 2004 , Pages 1307-1314. [9] N.D. Yordanov and Y. Karakirova, EPR of gamma irradiated solid sucrose and UV spectra of its solution. An attempt for calibration of solid state/EPR dosimetry, Radiation Measurements, Volume 42, Issue 3, March 2007, Pages 347-351.

[10] Z.M. Da Costaa, W.M. Pontuschkaa, L.L. Camposb, A comparative study based on dosimetric properties of different sugars, Applied Radiation and Isotopes 62 (2005) 331-336.

[11] Supe, A.A. and Tiliks, Yu.E., 1994. Optical absorption of irradiated carbohydrates. High Energy Chemistry 28, p. 193. 


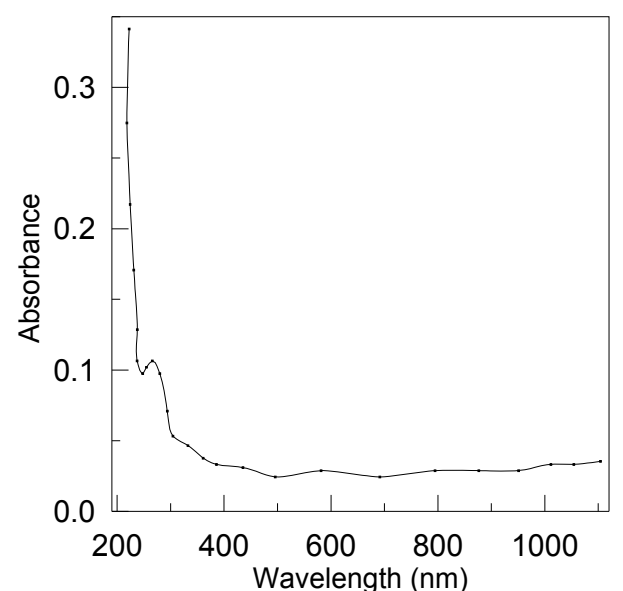

Fig.1: Absorbance spectrm of sugar aquous solution with concentration $5 \%$.

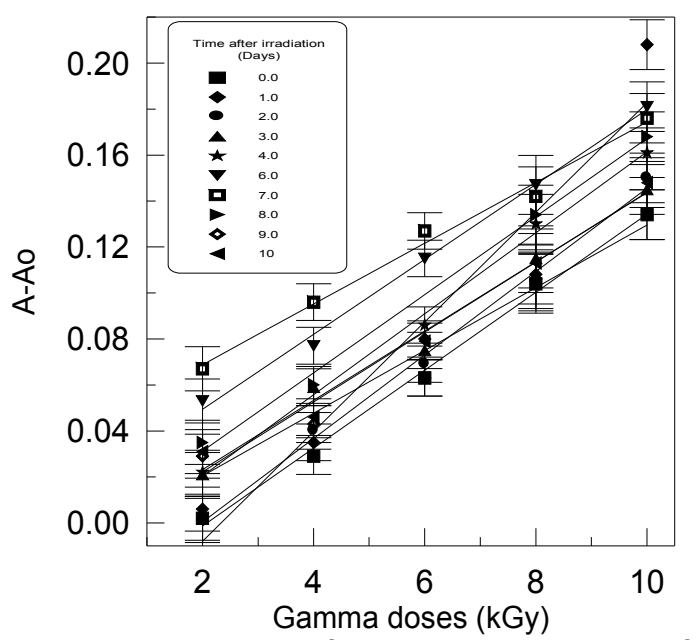

Fig.3: Variation of (A-Ao) with gamma dose for different times after irradiation (5\% fresh solution).

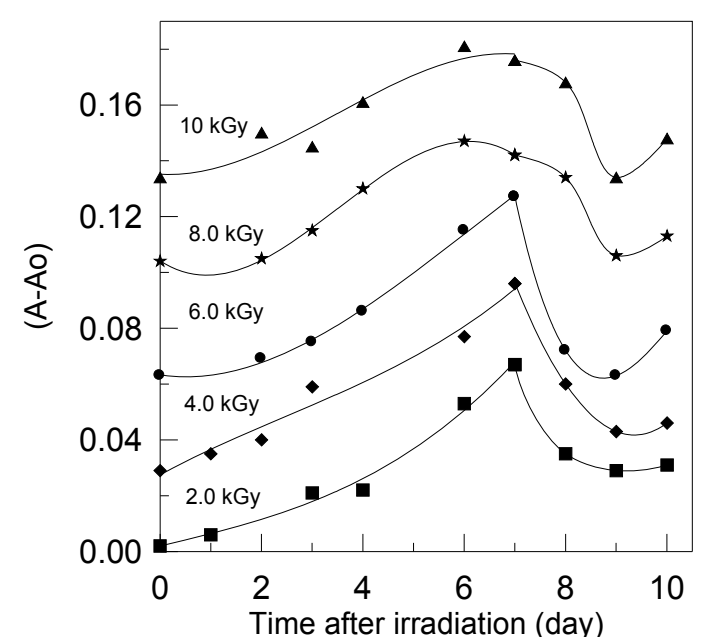

Fig.5: Fading effect of $5 \%$ fresh samples for different gamma doses.

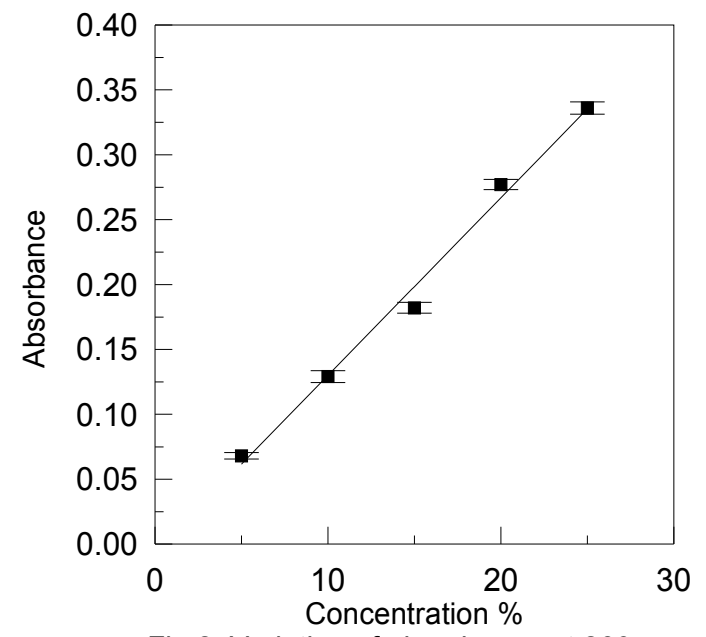

Fig.2: Variation of absorbance at 269nm with concentration.

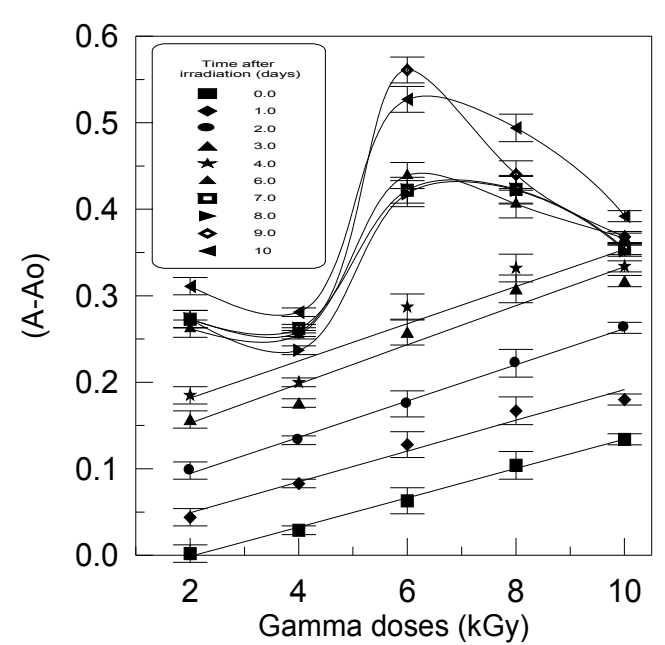

Fig.4: Variation of (A-Ao) with gamma dose for different times after irradiation ( $5 \%$ once solution).

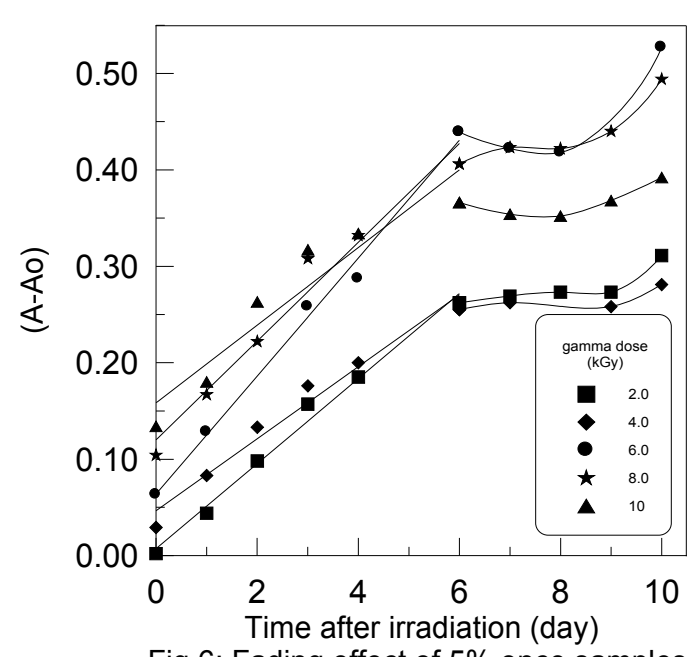

Fig.6: Fading effect of 5\% once samples for different gamma doses. 


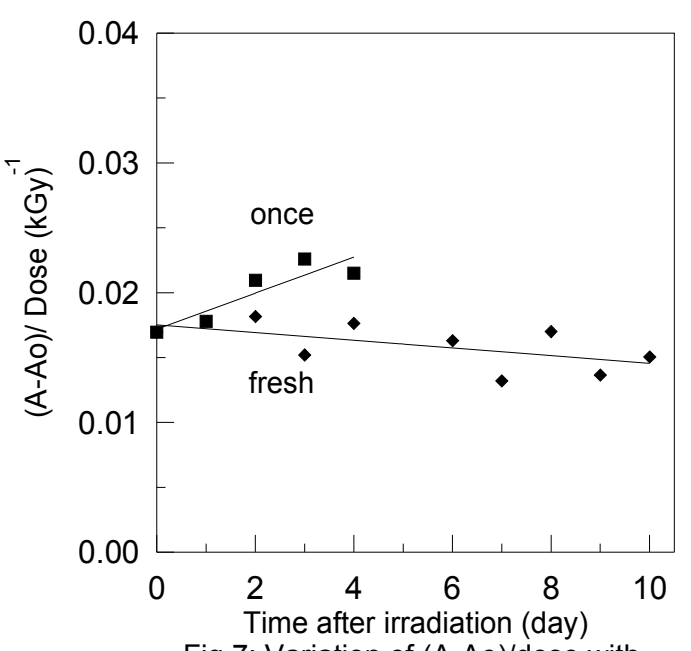

Fig.7: Variation of (A-Ao)/dose with time after irradiation.

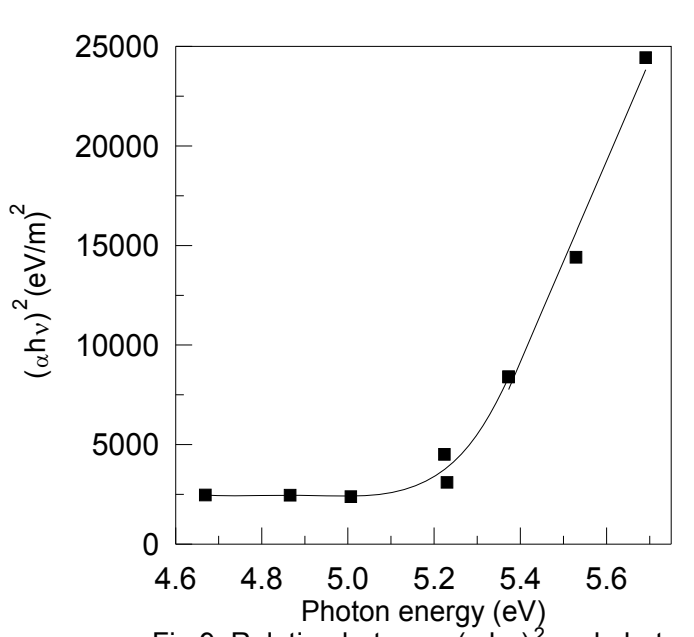

Fig.9: Relation between $\left(\alpha h_{\nu}\right)^{2}$ and photon energy ( $5 \%$ concentration).

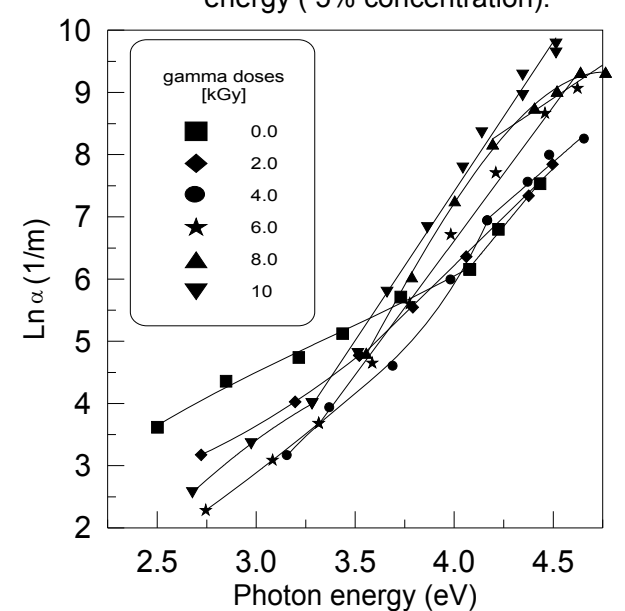

Fig.11: Variation of $\operatorname{Ln}(\alpha)$ with photon energy with gamma dose for once solution ( $5 \%$ concentration).

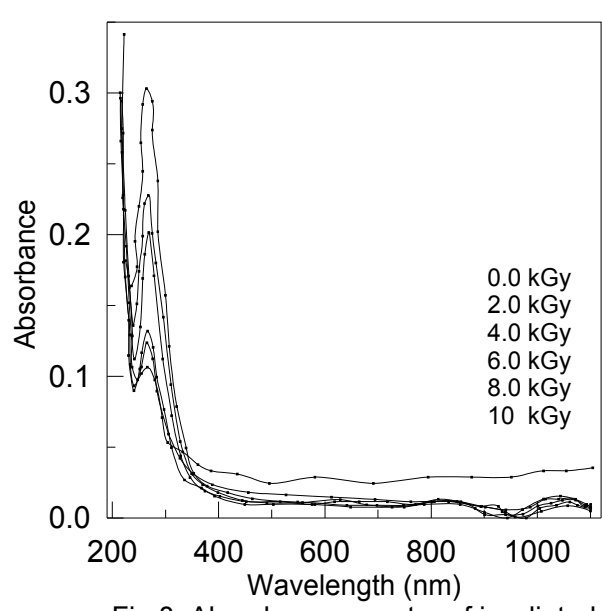

Fig.8: Absorbance spectra of irradiated samples(0-10kGy)

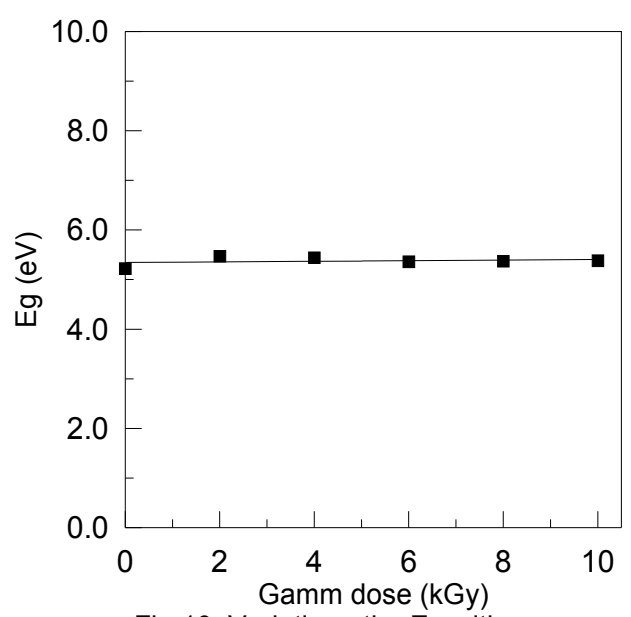

Fig.10: Variation othe Eg with gamma radiation dose (concentration 5\%).

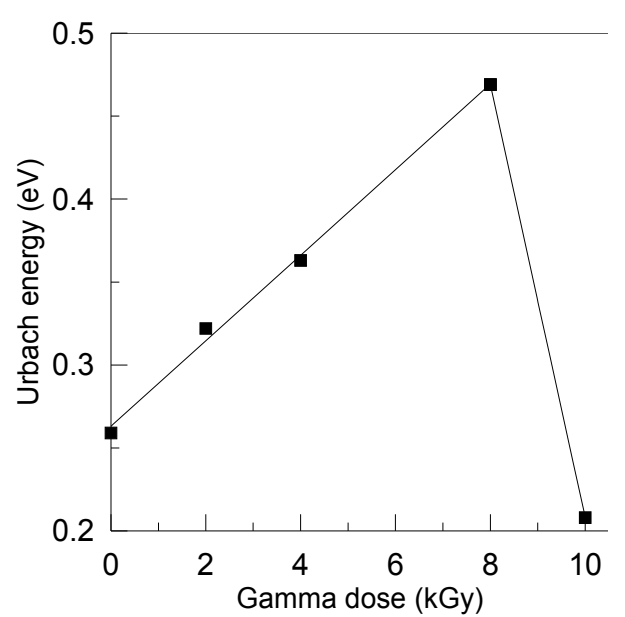

Fig.12: Variation of Urbach energy with gamma dose for once solution (5\%). 


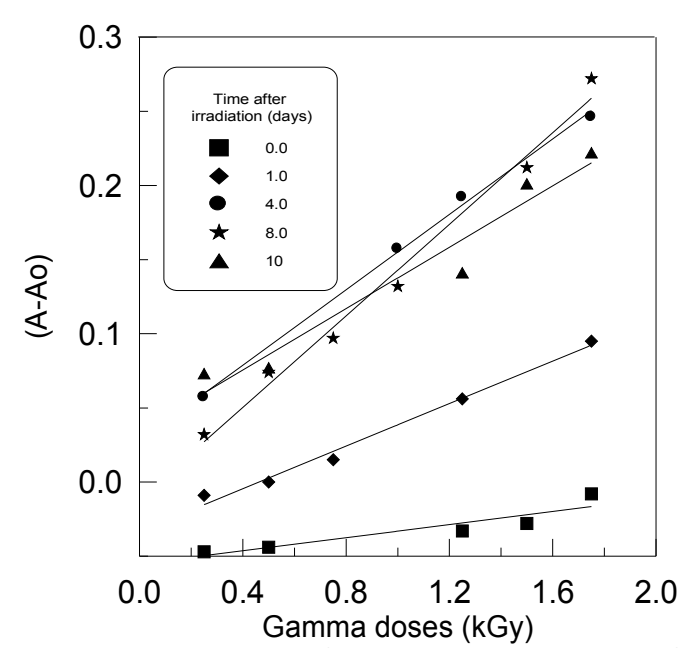

Fig.13: Variation of (A-Ao) with gamma dose for different times after irradiation (once solution).

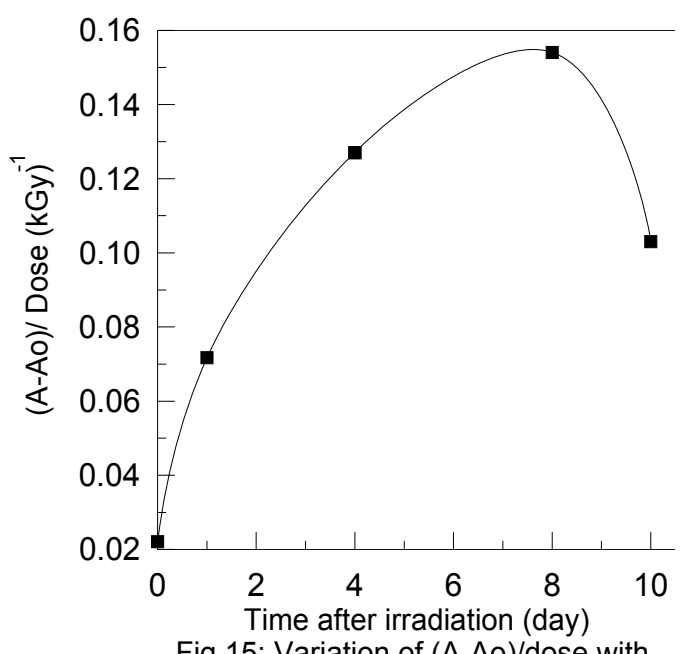

Fig.15: Variation of (A-Ao)/dose with time after irradiation (once sample).

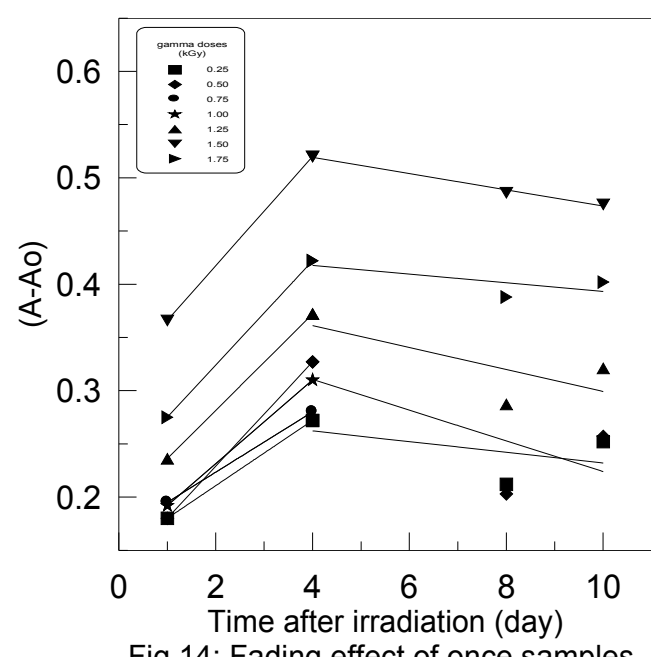

Fig.14: Fading effect of once samples for different gamma doses.

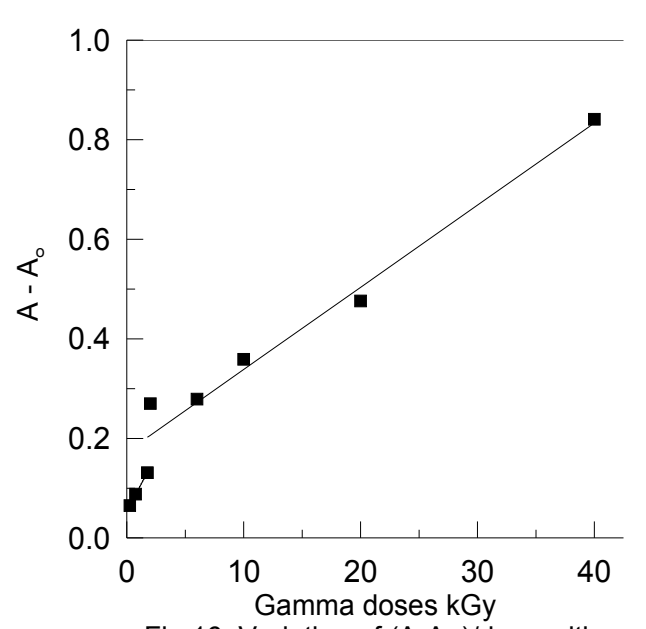

Fig. 16: Variation of (A-Ao)/dose with time after irradiation (once sample). 